\title{
MORTALITY AND CAUSES OF DEATH OF CHILDREN WITH DOWN'S SYNDROME IN SAN-IN DISTRICT, JAPAN
}

\author{
Kenzo TAKeSHITA, ${ }^{1}$ Teruko ToYofukU, ${ }^{1}$ and Masataka ARIMA ${ }^{2}$ \\ ${ }^{1}$ Division of Child Neurology, Tottori University Medical School, \\ Yonago 683, Japan \\ ${ }^{2}$ Division of Child Neurology, National Center for Nervous, \\ Mental and Muscular Disorders, 2620 Ogawa-Higashimachi, \\ Kodaira, Tokyo 187, Japan
}

\begin{abstract}
Summary One hundred and fifty six children with Down's syndrome who were born during 1969-1978 in San-in district, Japan were traced for a period from one year to ten years. Mortality and survival as well as causes of death, if applicable were studied. The largest number of deaths were observed during the first year of life. The survival fraction at 5 years of age was $0.697 \pm 0.041$. From ages 5 to 10 , no death was observed. The most significant cause of death in children with Down's syndrome was cardio-respiratory diseases ( 80.5 per cent). Mortality was especially high in both winter and spring. No correlation was observed between the early deaths and the distributions of paternal and maternal age at childbirth.
\end{abstract}

\section{INTRODUCTION}

The first life-table for patients with Down's syndrome was compiled in 1955 by Record and Smith (1955). Since then a number of life-tables have been published. In recent years, it has been suggested that the life expectancy of children with Down's syndrome has increased. The purpose of this paper is to present and analyze the data on the mortality and causes of death among children with Down's syndrome below 10 years in San-in district, Japan.

\section{MATERIALS AND METHODS}

The original material consisted of children with Down's syndrome liveborn during 1969-1978 in San-in district (Tottori Prefecture and Shimane Prefecture), in which the population was about $1,369,000$ in 1978 . Only cases with a positive result of the chromosome analysis or with an unambigous clinical picture were 
included. We attempted to obtain information from all public health centers, all prefectural institutions for handicapped children and all pediatric and gynecological clinics of the public hospitals in San-in district. The incidence and the analytical data on birth of the children with Down's syndrome were already reported by Toyofuku et al. (1980). All cases had been traced till 31st December, 1979 for the siudy. The observed period varies from one year to ten years. For those who died during the course of this study, we obtained information on the cause of death from the physician who attended on the child. When multiple causes of death were listed, we selected what seemed to be, in our opinion, the most contributory cause of the death and recorded it. For example, when the immediate cause of death was pneumonia in a child with congenital heart disease and heart congestion, the latter two were chosen as the cause of death.

\section{RESULTS}

A total of 156 children with Down's syndrome made up the study group: 86 (55.1 per cent) were males and 70 (44.9 per cent) were females. At the end of the study, a total of 111 were still alive, 41 had died and 4 could not be traced. Table 1 presents mortality and survival fraction for each age group. The mortality was the greatest under the age of one. The cumulative survival fraction at 5 years of age was $0.697 \pm 0.041$. All children who survived until 5 years of age were still alive on their 10th birthday. Superficially, survival fraction of children with Down's syndrome appears to be slightly in favor of males, but the difference was not significant.

Seasonal variation and causes of deaths are summarized in Tables 2 and 3 . Mortality was greater both in winter and spring than in the rest of the year. The

Table 1. Mortality and survival in 156 children with Down's syndrome.

\begin{tabular}{|c|c|c|c|c|c|c|}
\hline \multirow{2}{*}{$\frac{\begin{array}{c}\text { Age } \\
\text { interval }\end{array}}{0-}$} & \multirow{2}{*}{$\frac{\begin{array}{c}\text { No. of } \\
\text { children }\end{array}}{156^{*}}$} & \multicolumn{2}{|c|}{$\begin{array}{l}\text { No. of deaths } \\
\text { (male : female) }\end{array}$} & \multirow{2}{*}{$\frac{\text { Mortality }}{0.143}$} & \multicolumn{2}{|c|}{$\begin{array}{c}\text { Cumulative survival fraction } \\
\text { (standard error) }\end{array}$} \\
\hline & & 22 & $(12: 10)$ & & 1.000 & $(0.000)$ \\
\hline $1-$ & 113 & 7 & $(6: 1)$ & 0.062 & 0.857 & $(0.028)$ \\
\hline $2-$ & 97 & 7 & $(2: 5)$ & 0.072 & 0.804 & $(0.033)$ \\
\hline $3-$ & 80 & 3 & $(1: 2)$ & 0.038 & 0.746 & $(0.037)$ \\
\hline $4-$ & 69 & 2 & $(1: 1)$ & 0.029 & 0.718 & $(0.039)$ \\
\hline 5- & 59 & 0 & & 0.000 & 0.697 & $(0.041)$ \\
\hline $6-$ & 46 & 0 & & 0.000 & 0.697 & $(0.041)$ \\
\hline $7-$ & 32 & 0 & & 0.000 & 0.697 & $(0.041)$ \\
\hline $8-$ & 28 & 0 & & 0.000 & 0.697 & $(0.041)$ \\
\hline $9-10$ & 14 & 0 & & 0.000 & 0.697 & $(0.041)$ \\
\hline
\end{tabular}

* 4 of them could not be traced. 
Table 2. No. of deaths in different seasons.

\begin{tabular}{lccccc}
\hline & $\begin{array}{c}\text { Spring } \\
(3,4,5)\end{array}$ & $\begin{array}{c}\text { Summer } \\
(6,7,8)\end{array}$ & $\begin{array}{c}\text { Autumn } \\
(9,10,11)\end{array}$ & $\begin{array}{c}\text { Winter } \\
(12,1,2)\end{array}$ & Total \\
\hline Male & 8 & 2 & 3 & 9 & 22 \\
Female & 8 & 5 & 1 & 5 & 19 \\
Total & 16 & 7 & 4 & 14 & 41 \\
\hline Per cent & 39.0 & 17.1 & 9.8 & 34.2 & 100.0 \\
\hline
\end{tabular}

Table 3. Causes of deaths in present study.

\begin{tabular}{lcccc} 
& \multicolumn{3}{c}{ No. of deaths } & \multirow{2}{*}{ Per cent } \\
\cline { 2 - 4 } & Male & Female & Total & \\
\hline Cardiac insufficiency & 9 & 9 & 18 & 43.9 \\
Pneumonia & 9 & 6 & 15 & 36.6 \\
Leukemia & 0 & 3 & 3 & 7.3 \\
Intestinal obstruction & 2 & 0 & 2 & 4.9 \\
Measles & 1 & 0 & 1 & 2.4 \\
Cerebral thrombosis & 1 & 0 & 1 & 2.4 \\
Accident & 1 & 0 & 1 & 2.4 \\
\hline Total & 22 & 19 & 41 & 100.0 \\
\hline
\end{tabular}

two main causes of mortality were congenital heart disease ( 43.9 per cent) and respiratory disease, mostly pneumonia (36.6 per cent), i.e., 80.5 per cent of all deaths were attributable to them (Table 3). Of 41 deaths, 24 (58.5 per cent) occurred in children with positive heart murmur and 7 in those without murmur. In the remaining 10, no description was given. By contrast, of 111 survivors, only 27 (24.3 per cent) were reported as having heart murmur, 74 as negative and the remaining 10 as unknown. The difference was significant at 0.5 per cent level. Malignant conditions included three cases of childhood leukemia ( 7.3 per cent). There existed no correlation between mortality rate and birth order or birth weight of Down's syndrome. So didn't paternal or maternal age at birth.

\section{DISCUSSION}

The results of this study are in agreement with data from other workers (Brothers and Jago, 1945; Collmann and Stoller, 1963; Forssman and Åkesson, 1965), which indicate that many deaths of children with Down's syndrome occurred early in life. According to Collmann and Stoller (1963), 50 per cent of all deaths occurred during the first five years of life. The same trend was observed in the present study indicating that it was not affected by the increase of life expectancy 
in the past two decades (Richards and Sylvester, 1969; Jackson et al., 1968, Deaton, 1973). On the other hand, all children who survived until 5 years of age were alive on their 10th birthday. In a study of Preston et al. (1972), 94.5 per cent of all males and 95.0 per cent of all females who survived until 5 years of age were alive on their 10th birthday. It appears that the first 5 years of life is a very critical period for a child with Down's syndrome.

The two most common causes of death are respiratory and cardiac diseases (Öster et al., 1975). According to Hurst and Logue (1970), 50 per cent of patients with Down's syndrome had congenital heart disease, a combination of cardiac congestion and pneumonia being the most common cause of death among them. In the present series, cardio-respiratory diseases accounted for about 80 per cent of all deaths in reasonable agreement with Öster et al. (1975), where the same accounted for 62 per cent.

Three children died of leukemia.

There observed a seasonal variation in the mortality, i.e., high in both winter and spring. This holded true when fatalities of cardio-respiratory diseases were separately considered.

This study was aided by the grant from the Ministry of Health and Welfare of Japan for the Handicapped Children, and the scientific research grant from the Ministry of Education, Japan.

\section{REFERENCES}

Brothers, C.R.D., and Jago, G.C. 1954. Report on the longevity and the cause of death in mongoloidism in the State of Victoria. J. Ment. Sci. 100: 580-586.

Collmann, R.D., and Stoller, A. 1963. Data on mongolism in Victoria, Australia: prevalence and life expectation. J. Ment. Defic. Res. 7: 60-68.

Collmann, R.D., and Stoller, A. 1963. A life table for mongols in Victoria, Australia. J. Ment. Defic. Res. 7: 53-59.

Deaton, J.G. 1973. The mortality rate and cause of death among institutionalized mongols in Texas. J. Ment. Defic. Res. 17: 117-122.

Forssman, H., and Akesson, H.O. 1965. Mortality in patients with Down's syndrome. J. Ment. Defic. Res. 9: 146-149.

Hurst, J.W., and Logue, R.B. 1970. The Heart (2nd ed.), McGraw-Hill Book Co., New York

Jackson, E.W., Turner, J.H., Klauber, M.R., and Norris, F.D. 1968. Down's syndrome: variation of leukemia occurrence in institutionalised populations. J. Chronic. Dis. 21 : 247-253.

Öster, J., Mikkelsen, M., and Nielsen, A. 1975. Mortality and life-table in Down's syndrome. Acta Paediatr, Scand. 64: 322-326.

Preston, S.H., Keyfitz, N., and Schoen, R. 1972. Causes of Death: Life Tables for National Populations. Seminar Press, New York.

Record, R.G., and Smith, A. 1955. Incidence, mortality and sex distribution of mongoloid defectives. Br. J. Prev. Soc. Med. 9: 10-15.

Richards, B.W., and Sylvester, P.E. 1969. Mortality trends in mental deficiency institutions. $J$. Ment. Defic. Res. 13: 276-292.

Toyofuku, T., Takeshita, K., and Arima, M. 1980. Down's syndrome. An epidemiological and genetical studies in San-in district, Japan (in Japanese). Acta Paediatr. Ipn. 84: 1278-1283 